\title{
Off-pump coronary artery bypass surgery: The implications of the evidence
}

\author{
Raimondo Ascione, MD \\ Gianni D. Angelini, FRCS
}

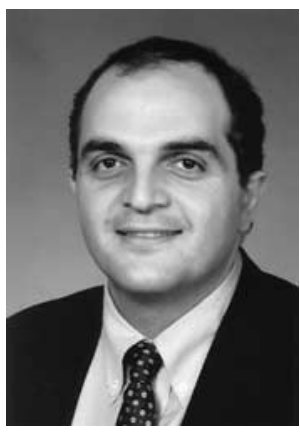

Dr Ascione

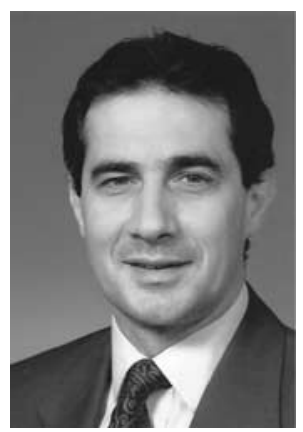

Dr Angelini

From the Bristol Heart Institute, University of Bristol, Bristol, United Kingdom.

Received for publication June 30, 2002; revisions requested July 1, 2002; revisions received July 30, 2002; accepted for publication Aug 6, 2002

Address for reprints: Gianni D. Angelini, MD, Professor of Cardiac Surgery, Bristol Heart Institute, Bristol Royal Infirmary, Bristol BS2 8HW, United Kingdom (Email: R.Ascione@bristol.ac.uk).

J Thorac Cardiovasc Surg 2003;125:779-81

Copyright (C) 2003 by The American Association for Thoracic Surgery

$0022-5223 / 2003 \$ 30.00+0$

doi: $10.1067 / \mathrm{mtc} .2003 .11$

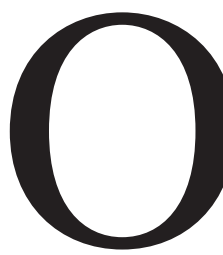

ff-pump coronary artery bypass surgery (OPCAB) has experienced a revival since the early 1990s, with the emergence of two schools of thought. The school in favor of OPCAB emphasizes the potential of reducing morbidity while allowing undeveloped countries to access a program of coronary surgery at reduced cost. The other school expresses concern because of the potential for intraoperative myocardial ischemia, suboptimal anastomoses, and a protracted learning curve. Progressively, a variety of innovative techniques and enabling instruments have made OPCAB a standard procedure. Concomitantly, a large number of observational, case-matched, and, not least, prospective randomized studies have been published. In the absence of recognized guidelines, the decision whether to use on-pump or off-pump techniques is often left to individual surgeons. Many are enthusiastically jumping on the OPCAB bandwagon, whereas others are adopting an even more conservative approach. The result is a significant divergence in the treatment of patients, often even within the same unit, the impact of which remains uncertain. There is an urgent need to evaluate the available evidence in a measured and scientific fashion to prevent this gut feeling-based disparity of treatment.

\section{The Evidence}

The ancient Romans aiming to please the people used to say, "Vox populi, vox dei!" when deciding in the arena whether to put their thumbs up or (mostly) down. In the same way, when auditing the efficacy of a new technique, the surgical scientific community has shown lack of methodology and consistency, in most cases leaving events to sort themselves out. This has been fortunate with the advent in coronary surgery of the left internal thoracic artery graft $^{1}$ but rather disappointing in other cases, such as the advent of transmyocardial laser revascularization. ${ }^{2}$

With $\mathrm{OPCAB}$, the surgical scientific community has tended to turn its thumb down, continually demanding evidence. Actually, this has been fortunate, because many off-pump centers have been prompted to design studies of good quality, producing a number of prospective randomized trials, case-matched reports, and observational reports. The best of them, as determined by study design, size of the surgical population, and quality of the statistical analysis used, are discussed here. Beating Heart Against Cardioplegic Arrest Study (BHACAS) 1 and 2 were two single-center randomized trials carried out on a total population of 401 patients undergoing elective operations (200 of which were performed off pump). ${ }^{3}$ Completeness of revascularization was similar between the two groups, and in-hospital mortality did not differ ( $1 \%$ for on pump vs $0 \%$ for off pump). Benefits associated with OPCAB included significant reductions in chest infection, inotropic requirement, incidence of arrhythmias, total chest tube drainage and consequent transfusion requirement, intubation time, intensive care, hospital stay, and costs. The outcome of a multicenter randomized trial in a cohort of 281 patients (142 undergoing operations off pump) was reported by Van Dijk and coworkers ${ }^{4}$ and showed no differences in terms of in-hospital mortality and morbidity. The patients undergoing off-pump surgery, however, had a shorter ventilation time, were discharged 1 day 
earlier, and had a reduction of $41 \%$ in release of creatine isoenzyme MB relative to the on-pump patients.

Although the results of prospective randomized studies are rightly considered the criterion standard, they are not powered to detect differences in more than few chosen end points. Moreover, their findings cannot be uncritically extended to an entire surgical population if there are restricted exclusionary criteria. For these reasons very large retrospective studies, supported by sophisticated statistical analysis might be equally helpful. A recent study from Magee and colleagues $^{5}$ in a cohort of 8449 patients (1983 patients with operations performed off pump) used propensity score analysis to demonstrate that elimination of cardiopulmonary bypass improves early survival in patients undergoing multivessel coronary artery bypass grafting. Similarly, Cleveland and coworkers, ${ }^{6}$ in a multicenter retrospective riskadjusted analysis of 118,140 coronary artery bypass grafting procedures without concomitant surgery drawn from the National Adult Cardiac Surgery Database of The Society of Thoracic Surgeons (11,717 of which were OPCAB), showed significant benefits associated with OPCAB. These included decreases in operative mortality (from 2.9\% to $2.3 \%$ ) and major complications such as deep sternal infection, bleeding, renal failure, and prolonged ventilation (from $14.1 \%$ to $10.6 \%$ ). Similar results were reported by Calafiore and associates. ${ }^{7}$ However, a major limitation of this kind of study is the potential for bias related to differences in patient selection, surgical technique, and, not least, surgical skill.

Comparisons assessing inflammatory and coagulation activation and subsystem organ dysfunction also deserve mention. Several studies have reported a significant attenuation of inflammatory activation ${ }^{8,9}$ and coagulation impairment ${ }^{3,5,7,10}$ with $\mathrm{OPCAB}$ relative to conventional surgery. The lower release of troponin I during $\mathrm{OPCAB}^{4,11}$ suggests limited myocardial injury, a possible explanation for the reduced incidence of postoperative arrhythmias and inotropic support among these patients. ${ }^{3,12} \mathrm{~A}$ protective effect of $\mathrm{OPCAB}$ on renal function is suggested both by biochemical evaluation in patients undergoing elective operations ${ }^{13}$ and by the analysis of major clinical outcomes among patients at higher risk for postoperative renal dysfunction either from diabetes $^{6}$ or from preoperative non-dialysis-dependent renal insufficiency. ${ }^{14} \mathrm{~A}$ word of caution is needed regarding the efficacy of OPCAB in preventing neuropsychologic dysfunction. Although a lower release of S100 protein was recorded soon after off-pump coronary surgery, the results regarding early and late cognitive dysfunction are controversial in the sense that they have been either better or similar when compared with conventional surgery. ${ }^{15,16}$ There are many more studies in the literature on OPCAB, and several on patients at higher risk who might benefit the most from this procedure. The vast majority of these studies report benefits associated with $\mathrm{OPCAB}$, whereas the rem- nant minority suggest that OPCAB is as good as conventional surgery in terms of mortality and morbidity. ${ }^{17-19}$

One of the major criticisms of OPCAB is the performance of suboptimal anastomoses, with the potential for poor long-term results. The late clinical outcomes of the two BHACAS trials $(29.3 \pm 7.4$ and $15.7 \pm 5.5$ months for BHACAS 1 and 2 respectively) showed no differences between groups in terms of late mortality, cardiac-related events, and need for further coronary revascularization procedure. ${ }^{3}$ These results are similar to those reported by van Dijk and coworkers ${ }^{4}$ at 1 month of follow-up and are supported by angiographic evidence reported by others. ${ }^{7,20,21}$ Considering that conventional coronary surgery has benefited from 30 years of surgical technical evolution, the results of developed OPCAB are quite encouraging in light of its relatively short life. Perhaps before the BHACAS data OPCAB without stabilization devices and intracoronary shunts suggested somewhat poorer long-term outcome. ${ }^{22}$

\section{The Implications of the Evidence}

Since the renascence of OPCAB, its application has tended to increase dramatically, although it still varies from $0 \%$ to $100 \%$ depending on the center. This may be a simple reflection of the different phase of the learning curve at each center; those that started their OPCAB programs several years ago with small numbers of selected patients are now performing this operation in $90 \%$ of their cases. $67,18,21,23,24$

Thousands of OPCAB procedures each year are already being performed as consequence of the possibility of reducing morbidity, but this may also have a welcome economic spin-off. The calculation of the in-hospital costs of the first BHACAS trial showed a saving of about $25 \%$ per patient. ${ }^{22}$ However, the enthusiasm for OPCAB has not been uniform within developed countries, as judged by the amount of literature produced. The adoption of OPCAB in the United Kingdom (for example) has rightly or wrongly been slower than France, German, Italy, or the United States, and this could be due to different approaches of these countries to a recognized teaching program.

The evidence supporting OPCAB deserves for the scientific community to call for a forum and make specific recommendations. If it is agreed that the evidence is against $\mathrm{OPCAB}$, then those performing such procedures should stop because they are affecting the quality of care of thousands of patients worldwide. If, on the other hand, it is agreed that the evidence for benefit of OPCAB is conclusive, then the implications are of a different order. Implementation of OPCAB could improve the quality of care for many patients operated on each year with conventional techniques. This predicts the need for a recognized teaching program that addresses genuine concerns about OPCAB, the organization of dedicated audit systems of OPCAB, and, not least, consideration of the ethical issue of those research 
projects designed to randomly assign patients to both techniques purely for study purposes.

\section{References}

1. Loop FD, Lytle BW, Cosgrove DM, Stewart RW, Goormastic M, Williams GW, et al. Influence of the internal-mammary-artery graft on 10-year survival and other cardiac events. N Engl J Med. 1986;314:1-6

2. Schofield PM, Sharples LD, Caine N, Burns S, Tait S, Wistow T, et al. Transmyocardial laser revascularisation in patients with refractory angina: a randomised controlled trial. Lancet. 1999;353:519-24.

3. Angelini GD, Taylor FC, Reeves BC, Ascione R. Early and midterm outcome after off-pump and on-pump surgery in Beating Heart Against Cardioplegic Arrest Studies (BHACAS 1 and 2): a pooled analysis of two randomized controlled trials. Lancet. 2002;359:1194-9.

4. van Dijk D, Nierich AP, Jansen EW, Nathoe HM, Suyker WJ, Diephuis JC, et al. Early outcome after off-pump versus on-pump coronary bypass surgery. Results from a randomized study. Circulation. 2001;104:1761-6.

5. Magee MJ, Jablonski KA, Stamou SC, Pfister AJ, Dewey TM, Dullum $\mathrm{MK}$, et al. Elimination of cardiopulmonary bypass improves early survival for multivessel coronary artery bypass patients. Ann Thorac Surg. 2002,73:1196-203.

6. Cleveland JC, Shroyer AL, Chen AY, Peterson E, Grover FL. Offpump coronary artery bypass grafting decreases risk-adjusted mortality and morbidity. Ann Thorac Surg. 2001;72:1282-8.

7. Calafiore AM, Di Mauro M, Contini M, Di Giammarco G, Pano M, Vitolla G, et al. Myocardial revascularization with and without cardiopulmonary bypass in multivessel disease: impact of the strategy on early outcome. Ann Thorac Surg. 2001;72:456-62.

8. Diegeler A, Doll N, Rauch T, Haberer D, Walther T, Falk V, et al. Humoral immune response during coronary artery bypass grafting. A comparison of limited approach, "off-pump" technique, and conventional cardiopulmonary bypass. Circulation. 2000;102(19 Suppl 3): III95-100.

9. Ascione R, Lloyd CT, Underwood MJ, Lotto AA, Pitsis AA, Angelini GD. Inflammatory response after coronary revascularization with or without cardiopulmonary bypass. Ann Thorac Surg. 2000;69:1198204.

10. Ascione R, Williams S, Lloyd CT, Sundaramoorthi T, Pitsis AA, Angelini GD. Reduced postoperative blood loss and transfusion requirement after beating-heart coronary operations: a prospective randomized study. J Thorac Cardiovasc Surg. 2001;121:689-96.

11. Ascione R, Lloyd CT, Gomes WJ, Caputo M, Bryan AJ, Angelini GD. Beating versus arrested heart revascularization: evaluation of myocardial function in a prospective randomized study. Eur J Cardiothorac Surg. 1999;15:685-90.
12. Ascione R, Caputo M, Calori G, Lloyd CT, Underwood MJ, Angelini GD. Predictors of atrial fibrillation after conventional and beating heart coronary surgery: a prospective randomized study. Circulation. 2000;102:1530-5.

13. Ascione R, Lloyd CT, Underwood MJ, Gomes WJ, Angelini GD. On pump versus off pump coronary revascularization: evaluation of renal function. Ann Thorac Surg. 1999;68:493-8.

14. Ascione R, Nason G, Al_Ruzzeh S, Ko C, Ciulli F, Angelini GD. Coronary revascularization with or without cardiopulmonary bypass in patients with preoperative nondialysis dependent renal insufficiency. Ann Thorac Surg. 2001;72:2020-5.

15. Diegeler A, Hirsch R, Schneider F, Schilling LO, Falk V, Rauch T, et al. Neuromonitoring and neurocognitive outcome in off-pump versus conventional coronary bypass operation. Ann Thorac Surg. 2000;69: $1162-6$.

16. Taggart DP, Browne SM, Halligan PW, Wade DT. Is CPB still the cause of cognitive dysfunction after cardiac operations? I Thorac Cardiovasc Surg. 1999;118:414-20.

17. Ascione R, Reeves BC, Rees K, Angelini GD. Effectiveness of coronary artery bypass grafting with or without cardiopulmonary bypass in overweight patients. Circulation. 2002;106:1764-70.

18. Chamberlain HH, Ascione R, Reeves BC, Angelini GD. Evaluation of effectiveness of off-pump coronary artery bypass surgery in high-risk patients: an observational study. Ann Thorac Surg. 2002;73:1866-73.

19. Sabik JF, Gillinov AM, Blackstone EH, Vacha C, Houghtaling PL, Navia J, et al. Does off-pump coronary surgery reduce morbidity and mortality? J Thorac Cardiovasc Surg. 2002;124:698-707.

20. Puskas JD, Thourani VH, Marshall JJ, Dempsey SJ, Steiner MA, Sammons $\mathrm{BH}$, et al. Clinical outcomes, angiographic patency, and resource utilization in 200 consecutive off-pump coronary bypass patients. Ann Thorac Surg. 2001;71:1477-83.

21. Cartier R, Brann S, Dagenais F, Martineau R, Couturier A. Systematic off-pump coronary artery revascularization in multivessel disease: experience of three hundred cases. J Thorac Cardiovasc Surg. 2000; 119:221-9.

22. Gundry SR, Romano MA, Shattuck OH, Razzouk AJ, Bailey LL. Seven-year follow-up of coronary artery bypasses performed with and without cardiopulmonary bypass. J Thorac Cardiovasc Surg. 1998; 115:1273-7.

23. Caputo M, Chamberlain MH, Özalp F, Underwood MJ, Ciulli F, Angelini GD. Off-pump coronary operations can be safely taught to cardiothoracic trainees. Ann Thorac Surg. 2001;71:1215-9.

24. Karamanoukian HL, Panos AL, Bergsland J, Salerno TA. Perspectives of a cardiac surgery resident-in-training on off-pump coronary bypass operation. Ann Thorac Surg. 2000;69:42-5.

25. Ascione R, Lloyd CT, Underwood MJ, Lotto AA, Pitsis AA, Angelini GD. Economic outcome of off-pump coronary artery bypass surgery: a prospective randomized study. Ann Thorac Surg. 1999;68:2237-42. 